\title{
Cerebral oedema and the water content of normal white matter ${ }^{1}$
}

\author{
MASAZUMI ADACHI AND IRWIN FEIGIN \\ From the Departments of Pathology, New York University Medical Center and Bellevue Hospital, \\ New York, U.S.A.
}

The distribution of the increment of fluid in the human brain in cerebral oedema is not uniform. Obviously, cerebral oedema is often local, being present in the vicinity of a focal oedema-producing lesion such as a metastatic carcinomatous nodule. Of greater significance is the tendency to involve white matter with great severity, while sparing or almost sparing the adjacent gray matter. These tissues are so dissimilar that such a difference in reactivity is readily accepted, though the precise mechanism involved in this difference is well worth establishing. Of equal interest is the tendency for oedema, which is relatively severe in the deeper portions of the white matter, to spare the arcuate zone of the white matter, that portion just beneath the cortex. The arcuate and deep portions of the white matter are so similar that this difference in reactivity is a most intriguing problem. The corpus callosum and some other areas may also have a lesser tendency to involvement in oedema.

This study will present evidence that there is a difference in the water content of the arcuate and deeper white matter in the normal brain, and that it is possible that this difference is a factor in determining the degree of involvement of these tissues in cerebral oedema. The corpus callosum is intermediate in both respects.

\section{OBSERVATIONS}

$A$ Coronal sections of a group of formalin-fixed normal human brains were exposed to the air at room temperature. The brains had been fixed for seven to 14 days in $20 \%$ formalin containing $1 \%$ acetic acid, and washed in tap water before coronal section. Immediately after coronal section, the white matter appeared uniform, no distinction being visible between the arcuate and the deeper portions of the

${ }^{1}$ This study was supported in part by research grant HE-02872 of the National Heart Institute of the United States Public Health Service, and forms part of a study of cerebral vascular diseases at Bellevue Hospital by the Cornell-New York University study group
on cerebral vascular disease. white matter. As drying occurred, portions of the deeper white matter assumed a gray-brown coloration (Fig. 1) and later were very slightly retracted below the level of the cortex. The arcuate zone, however, remained white and could be readily differentiated from the deeper white matter by the difference in colour. This change was most obvious after about four hours of drying. As drying continued, observations became difficult, with irregular mottled

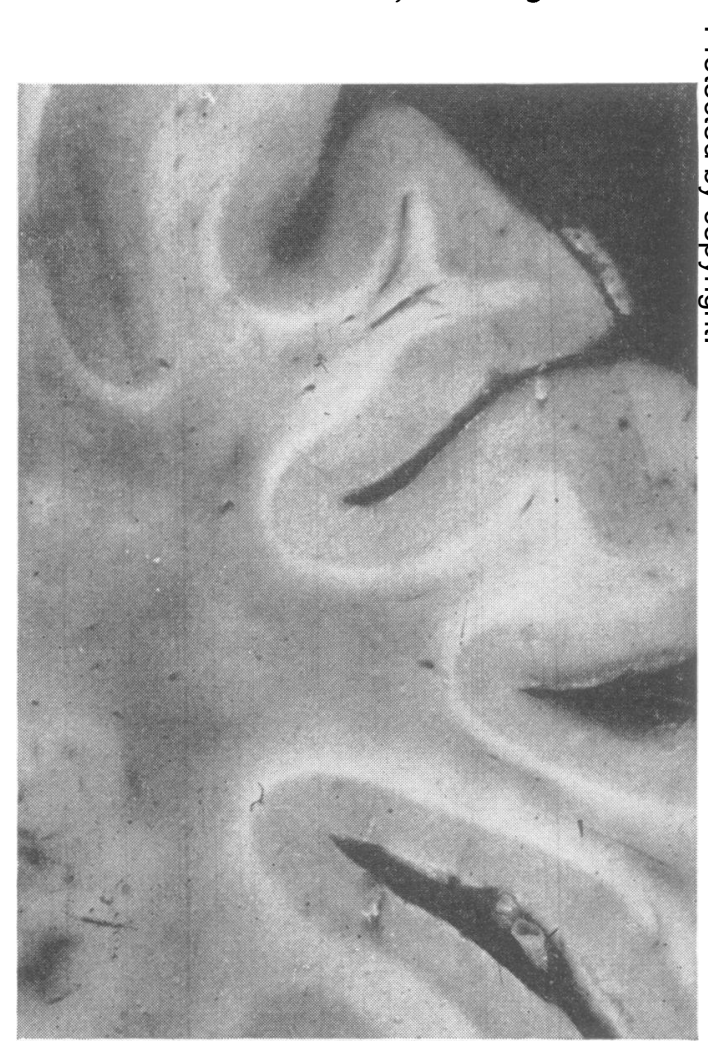

FIG. 1. Normal brain, dried in air for four hours at room temperature. The deep white matter is discoloured, while the arcuate zone retains its normal white colour. $\times 2$. 
zones assuming a dry, leathery, discoloured appearance.

The phenomenon is not consistent, is variable in intensity from brain to brain, and in different portions of the same brain. It is, however, an absurdly simple way to demonstrate a difference between arcuate and deeper white matter, and suggested the study which follows.

$B$ Samples of the arcuate white matter, of the deeper white matter, of the corpus callosum, and of the cortex of a series of 10 normal human brains, were analysed for their water content. The brains were from individuals 45 to 60 years of age, who had been essentially neurologically normal in life. The brains showed no significant pathological changes. They had been fixed for 10 to 14 days in $20 \%$ formalin with $1 \%$ acetic acid, and washed in tap water.

Samples were taken immediately after coronal section, and were all from the frontal lobes and the corpus callosum. A smooth surfaced cuboid block of tissue, approximately $1 \mathrm{~cm}$. in diameter, was prepared, containing cortex, arcuate white matter, and some deeper white matter. Using oblique light, the arcuate zone could be distinguished from the deeper white matter, presumably due to the difference in the direction of the fibres, and the arcuate tissues were removed by scalpel. The thickness of the arcuate zone as indicated by earlier studies of cerebral oedema, and in the observations described in section $A$ above, also served as a guide. The first specimen taken was from the arcuate zone (sample A) and this was blotted dry with filter paper, and weighed within three minutes of coronal sectioning. Samples of deep white matter (sample B) were taken from an adjacent area and weighed within the next 30 seconds, and thereafter the same was done with samples of corpus callosum (sample C) and of the cortex (sample D). The sampling was then repeated, with a second sample of arcuate zone (sample E) being taken, blotted dry and weighed approximately five minutes after coronal section, and samples of deep white matter (sample F), corpus callosum (sample G), and cortex (sample H) were quickly taken and weighed in turn.

Each sample was placed in an incubator at $56^{\circ} \mathrm{C}$., and weighed periodically thereafter for a total of 144 hours. In each instance, the weight decreased with time, 95 to $99 \%$ of the loss occurring in the first 24 hours, and a constant level being reached at 120 hours. The decrement in weight is assumed to represent readily volatile water, and is expressed in Table I as a fraction (percentage) of the original wet weight. Figures for nine of the 10 cases are given in the Table. The tenth case was discarded since the differences between the duplicate samples of the same tissue, i.e., $\mathrm{A}$ and $\mathrm{E}, \mathrm{B}$ and $\mathrm{F}$, etc., were considered excessive. This may be attributed to difficulties in sampling, which resulted in a considerable delay in completing the sampling and weighing process.

The difference between the water content of the arcuate white matter (18 observations) and that of the deep white matter (18 observations) is highly significant $(P<0.01)$. The difference in water content between the deep white matter and the corpus callosum is also significant, but barely so $(P<0.05)$.

As an ancillary study, the water content of cortex, deep white matter, and arcuate white matter of two fresh (unfixed) normal human brains was determined in a similar fashion. These results are included in Table I.

TABLE I

READILY VOLATILE WATER ( $\%$ WET WEIGHT)

$\begin{array}{llll}\text { Arcuate } & \text { Deep } & \text { Corpus } & \text { Cortex } \\ \text { White Matter } & \text { White Matter Callosum } & \end{array}$

\begin{tabular}{|c|c|c|c|c|c|c|c|c|}
\hline \multicolumn{9}{|c|}{ Fixed Brains } \\
\hline \multirow{10}{*}{$\begin{array}{l}1 \\
2 \\
3 \\
4 \\
5 \\
6 \\
7 \\
8 \\
9\end{array}$} & $A$ & \multirow{2}{*}{$\underset{80 \cdot 2}{E}$} & \multirow[t]{2}{*}{$\begin{array}{c}B \\
70 \cdot 3\end{array}$} & $F$ & C & $\boldsymbol{G}$ & \multirow{2}{*}{$\underset{83 \cdot 6}{D}$} & \multirow{2}{*}{$\underset{85.8}{H}$} \\
\hline & $80 \cdot 1$ & & & $70 \cdot 8$ & $77 \cdot 1$ & $70 \cdot 8$ & & \\
\hline & $81 \cdot 2$ & $78 \cdot 8$ & 72.8 & $70 \cdot 8$ & $73 \cdot 7$ & $78 \cdot 3$ & 83.7 & 86.5 \\
\hline & $80 \cdot \overline{8}$ & $78 \cdot 3$ & $72 \cdot 0$ & $72 \cdot 2$ & $70 \cdot 8$ & $72 \cdot 5$ & $84 \cdot 5$ & 83.8 \\
\hline & 78.5 & 76.8 & 74.0 & $68 \cdot 2$ & $72 \cdot 6$ & $70 \cdot 4$ & $87 \cdot 5$ & 85.0 \\
\hline & $77 \cdot 1$ & 80.0 & 73.8 & $67 \cdot 8$ & $71 \cdot 3$ & $77 \cdot 6$ & 85.5 & 84.6 \\
\hline & 80.4 & $77 \cdot 4$ & 71.4 & $72 \cdot 8$ & $74 \cdot 3$ & 76.5 & $86 \cdot 3$ & 86.0 \\
\hline & $78 \cdot 2$ & $76 \cdot 8$ & $68 \cdot 2$ & $71 \cdot 5$ & $70 \cdot 6$ & $74 \cdot 0$ & 88.2 & 85.4 \\
\hline & $78 \cdot 2$ & $79 \cdot 0$ & $70 \cdot 8$ & $68 \cdot 7$ & $71 \cdot 0$ & $70 \cdot 2$ & $84 \cdot 6$ & 83.8 \\
\hline & $81 \cdot 0$ & $79 \cdot 1$ & $72 \cdot 2$ & $73 \cdot 2$ & 71.5 & 75.4 & $87 \cdot 3$ & 85.4 \\
\hline Mean & & & & & & & & \\
\hline \multicolumn{9}{|c|}{ Fresh (Unfixed) Brains } \\
\hline 1 & $77 \cdot 2$ & $76 \cdot 1$ & $71 \cdot 7$ & $69 \cdot 7$ & & & 83.6 & $84 \cdot 8$ \\
\hline $2^{1}$ & $79 \cdot 8$ & $77 \cdot 5$ & $69 \cdot 7$ & $74 \cdot 2$ & & & 87.9 & 86.5 \\
\hline & $78 \cdot 0$ & $78 \cdot 6$ & 72.7 & 68.9 & & & 88.0 & $87 \cdot 0$ \\
\hline Mean & 7 & & & & & & & \\
\hline
\end{tabular}

${ }^{1}$ Two separate areas in same brain.

$C$ The degree of swelling of the normal human brain during fixation was studied. A series of 21 brains was weighed at necrospsy and weighed again after fixation in $20 \%$ formalin- $1 \%$ acetic acid for one to two weeks, under the conditions applicable to the study described above. The change in weight, expressed as a percentage of the original weight, was: $+15 \cdot 4,+12 \cdot 4,+7 \cdot 5,+5 \cdot 8,+5 \cdot 0,+4 \cdot 2,+2 \cdot 3$, $+1 \cdot 5,+1 \cdot 4,+0 \cdot 8,+0 \cdot 7,0,0,-0 \cdot 7,-1 \cdot 0,-1 \cdot 9$, $-2 \cdot 6,-6 \cdot 1,-6 \cdot 7,-7 \cdot 7,-8 \cdot 1$. The median value was $+0.7 \%$. Nineteen of the 21 were within the range $\pm 10 \%$. (Of 21 brains fixed in non-acidified $10 \%$ formalin for comparison, 18 of 21 were within the range $\pm 10 \%$, and the median value was $+6.2 \%$.)

Small samples of normal unfixed human brain were fixed for 10 days in the standard $20 \%$ formalin$1 \%$ acetic acid mixture. The swelling of two samples of cortical gray matter, approximately $100 \mathrm{mg}$. in weight, was $+26 \%$ and $+31 \%$, respectively; the swelling of two samples of thalamic gray matter approximately $1 \mathrm{~g}$. in weight was $+17 \%$ and $+14 \%$, 
respectively. The swelling of two samples of deep white matter approximately $100 \mathrm{mg}$. in size was $+36 \%$ and $+47 \%$, respectively; of two samples of white matter approximately $1 \mathrm{~g}$. in size, $+23 \%$ and $+28 \%$, respectively.

\section{DISCUSSION}

The pathological characteristics of oedema of the human brain have been known for many years (Greenfield, 1939; Perret and Kernohan, 1943; Scheinker, 1947). Such oedema consists of an increment of fluid in the extracellular spaces of the white matter directly demonstrable by appropriate staining procedures, such as the Luxol blue-periodicacid Schiff stain (Feigin and Popoff, 1962). This is associated with marked regressive changes in the astrocytes (Feigin and Popoff, 1962 and 1963) which are probably permanent. There is a great tendency for the arcuate zone of the white matter to be spared (Greenfield, 1939; Feigin and Popoff, 1962 and 1963), and a lesser tendency for sparing of the corpus callosum, internal capsule, and possibly still other portions of the white matter (Greenfield, 1939). The gray matter is not visibly affected on gross examination or on light microscopic examination, unless this tissue be necrotic, as may occur with infarction or traumatic contusion.

Electron microscopists have questioned the validity of this concept of extracellular oedema (Gershenfeld, Wald, Zadunaisky, and de Robertis, 1959; Torack, Terry, and Zimmerman, 1959 and 1960; Luse and Harris, 1960), with evidence apparently so convincing as to lead the editor of an annual review in this field to conclude (Mackay, 1962-63): 'The recent electron microscopic denial of extracellular space and restriction of oedema to intracellular and especially intraglial water and electrolytes is now all but established, though the light microscopists (vide Feigin and Popoff, 1962) find some evidence of extracellular oedema'. While fully justified at that time, such a conclusion was apparently premature, since more recent electron microscopic studies do confirm the presence of a dilated extracellular space as in the classical concept (Raimondi, Evans, and Mullan, 1962; Gonatas, Zimmerman, and Levine, 1963; Long and Hartmann, 1965), when the proper tissues are examined under the proper circumstances. The changes in gray matter, stressed in the earlier electron microscopic studies, are quantitatively a very minor fraction of the observable changes in oedema, which are concentrated in the white matter. The subdivision of the latter into 'cerebral oedema' and 'cerebral swelling' (Zülch, 1943; Zimmerman, 1964) is not considered valid (Greenfield, 1939; Perret and Kernohan, 1943; Scheinker, 1947; Feigin, 1965). The relevance to human cerebral oedema of the possibly unique intramyelinic vacuoles, seen in triethyl tin intoxication (Aleu, Katzman, and Terry, 1963), remains to be clarified. These considerations are discussed at greater length in another publication (Feigin, 1965).

Our present study is concerned directly with the mechanisms related to the great tendency for the arcuate zone to be spared in cerebral oedema, and the lesser tendency for the corpus callosum and, possibly other portions of the white matter, to be less involved than the deep white matter. Morphologically, these tissues appear essentially similar. No difference in the number, distribution, size, and nature of the astrocytes is apparent in these tissues with gold techniques (Feigin and Popoff, 1962). The axons appear similar in appearance and density, but are arranged in different fashions. Most of the arcuate fibres lie tangential to the overlying cortex, while most of the fibres in the deeper white matter lie perpendicular to this structure. Experimental data relating the spread of oedema fluid to the fibre pattern have been recorded (Clasen, Cooke, Pandolfi, Boyd, and Raimondi, 1962). While the tangential arrangement of the arcuate fibres may serve as a barrier to the spread of fluid into this area, this factor would not be relevant to the sparing of the corpus callosum or internal capsule.

The current study suggests another point of distinction among these tissues (Table I). The arcuat white matter contains a significantly higher conten of readily volatile water $(79 \%)$ than the deeper white matter $(71.2 \%)$, approaching in this respect, the water content of the overlying cortex $(85.4 \%)$. The corpus callosum was intermediate in water content $73.3 \%$ in our study, $75.7 \%$ in that by StewartWallace (1939). For these tissues, an inverse relationship exists between the susceptibility to oedema and the height of the normal water content (Table II). The gray matter of the cortex differs fundamentally from the others, all areas of white matter, and different mechanisms may apply to this tissue. The precise site in which the water is contained, or its form, is not evident in our studies. The fact that the water is so readily volatile suggests that chemically it may be bound very loosely or not at all. One might speculate on the possibility that the excess water, such as that of the arcuate zone, lies in the extracellular compartment of these tissues, and that this serves as a barrier to further increments of fluid by spread from oedematous deeper tissues. One would have to assume that this high water content of normal arcuate tissues is compatible with its normal state even though, in oedema, such water concentration in the deeper tissues results in pathological changes and physiological dysfunction. At this time, such conjecture may not be meaningful. 
TABLE II

MEAN - - - READILY VOLATILE WATER (\% WET WEIGHT)

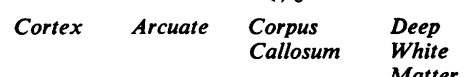

Matter

\begin{tabular}{lcccc}
\hline $\begin{array}{l}\text { Nine fixed brains } \\
\text { Two fresh brains }\end{array}$ & $85 \cdot 4$ & $79 \cdot 0$ & $73 \cdot 3$ & $71 \cdot 2$ \\
$\begin{array}{l}\text { Fresh (Stewart- } \\
\text { Wallace, 1939) }\end{array}$ & $86 \cdot 3$ & $77 \cdot 9$ & & $71 \cdot 2$ \\
$\begin{array}{c}\text { Fresh (Folch-Pi and } \\
\text { LeBaron, 1957) }\end{array}$ & $81-87$ & & $75 \cdot 7$ & $70 \cdot 7$ \\
$\begin{array}{l}\text { Susceptibility to } \\
\text { oedema }\end{array}$ & $(1)$ & 2 & 3 & $67-74$ \\
$\begin{array}{l}\text { oedema } \\
\text { (1) }\end{array}$ & & & & 4
\end{tabular}

While great care was exercised in sampling, consideration must be given to the possibility that the water content of the arcuate zone is, in truth, no greater than that of the deep white matter, but that the high water value of the sample represents contamination by cortical tissues. It can readily be calculated that the sample analysed would have to contain $55 \%$ cortex and $45 \%$ deep white matter, to give the value actually obtained ${ }^{\mathbf{1}}$, and we consider this most unlikely.

Most, though not all, of our water analyses have been performed on brains fixed in $20 \%$ formalin$1 \%$ acetic acid, and the validity of data so obtained warrants discussion. Our studies permit a comparison of tissues derived from the same fixed brain. If, for example, the arcuate and deeper white matter were truly identical, identical values for water content should be obtained in these tissues in any given brain, even if these values had been distorted by fixation. This is not the case. Actually, no distortion of the values for water content is observed for those tissues for which comparable values for fresh, unfixed brain are available (Table II). The values for cortex and deep white matter in the fixed brains are well within the normal range established for these tissues in fresh material (Folch-Pi and LeBaron, 1957). The water content of the arcuate white matter is much higher.

The impression appears to prevail that fixation of brain tissue causes such swelling that valid water analyses are impossible to obtain. This may be true in some circumstances, but it would appear evident that this is not true in the conditions employed in this study. There is evidence that such swelling is less with high concentrations of formalin than with low (Flatau, 1897; Hrdlička, 1906; Lagerlöf and Torgersruud, 1934; Bahr, Bloom, and Friberg, 1957). It is less in acid than in neutral or alkaline media (Gross and

\footnotetext{
${ }^{1}$ Let $\mathrm{C}$ be the quantity of cortex, and $\mathrm{D}$ the quantity of deep white matter respectively, in each gram of preserved 'arcuate' sample.

Total C $+\mathbf{D}=1$

Water $0.854 \mathrm{C}+0.712 \mathrm{D}=0.790$

$$
C=0.55 \quad D=0.45
$$
}

Lohaus, 1932; Lagerlöf and Togersruud, 1934). It is less in the larger brains of higher species of animals than those of lower species (Hrdlička, 1906). In the present study, evidence is presented that it is less in the whole brain than if small samples of the same tissue are fixed, and this impression is supported by surveying the other references cited in this paragraph, though, no other observer has specifically compared whole brains with small samples. With respect to all of these factors, the conditions employed in our studies would minimize the swelling anticipated. This report also includes, in section $C$ above, an estimate of the degree of swelling that actually occurs in human brains during fixation in $20 \%$ formalin- $1 \%$ acetic acid for one to two weeks. The median value for an increment of weight was $+0.7 \%$, with 19 of 21 brains showing less than a $\pm 10 \%$ change. The effect of such changes on the observed water values is very small. If the change were $+10 \%$ and uniformly distributed, a brain containing $70 \%$ water in the white matter, an average figure, would contain $72.2 \%$ water after fixation. ${ }^{2}$ The latter value is still well within the limits of normal. Calculations disclose that it would take an increment of weight of $26.9 \%$ uniformly distributed to increase the water content of the white matter from the lower limit of normal, $67 \%$, to the upper limit of normal, $74 \%$. For these reasons, we do not think that the high value for the water content of normal arcuate white matter, $79 \%$, is attributable to swelling due to fixation. Nonetheless, samples from two fresh, unfixed brains were studied as a final confirmation of the validity of the considerations just discussed, and the values obtained are included in the Tables. It is evident that these values are like those obtained in the fixed brains. Because of the difficulties in procuring arcuate samples of fresh brain tissue, it is possible that the values in the fixed brains are actually more accurate, though both are significantly different from those for deep white matter.

The distinction between arcuate and deeper white matter, which becomes evident on drying coronal sections after fixation, may simply reflect the quantitative difference in water concentrations in these areas, the higher concentration in the arcuate zone permitting a greater loss before discoloration becomes evident. In oedematous brains, which are more common at necropsy than originally thought; a distinction between these tissues is to be expected. It would also be well to note that at times in a brain that is improperly fixed the deeper white matter

$$
\begin{gathered}
{ }^{2} \text { Initially } \frac{\text { Water }}{\text { Total }}=\frac{0.7}{1}=0.70 \\
\text { after } 10 \% \text { swelling } \frac{\text { Water }}{\text { Total }}=\frac{0.8}{1 \cdot 1}=0.727
\end{gathered}
$$


may be discoloured and appear distinct from the overlying arcuate white matter even though drying had not apparently occurred. The difference in these tissues may be associated with differences in rate and character of fixation, and in other ways.

The differences in water content between the corpus callosum (73.3\%) and the deep white matter (71.2\%) are significant, but barely so. It is probable that the values obtained by Stewart-Wallace (1939), 75.7\% for corpus callosum, $\mathbf{7 0 . 7} \%$ for deep white matter, differ more significantly. It has been suggested by others that the corpus callosum may also be an area which tends to be spared in cerebral oedema (Greenfield, 1939). Our own observations on the localization of cerebral oedema in the human brain are considered inconclusive in this regard, though suggestive at times. Though elevated, the water content of the corpus callosum is not as high as that of the arcuate zone, and its immunity to involvement in cerebral oedema not as striking. Indeed, there may be still other differences among various portions of the white matter with respect to their normal water content and their susceptibility to involvement in cerebral oedema, and these may vary in degree. The internal capsule, for example, has also been described as being less likely to be affected in cerebral oedema (Greenfield, 1939).

\section{SUMMARY AND CONCLUSIONS}

The pathological features of oedema of the human brain were reviewed. The fundamentally extracellular localization of the increment of fluid and the relative sparing of the arcuate zone were emphasized.

In normal formalin-fixed human brains, drying resulted in a stage in which the deeper white matter became discoloured, while the overlying arcuate zone of the white matter was sharply distinguished by the retention of its normal white colour. Weighed samples of these tissues were dried at $56^{\circ} \mathrm{C}$., and the decrement of weight in each was ascertained, and interpreted as readily volatile water. In the conditions of this experiment, the water content of the arcuate zone was $79 \%$ of the original wet weight, while that in the deeper white matter was $71 \cdot 2 \%$. It is suggested that the difference in water content is related to the drying phenomenon described in this paper, and to the relative sparing of the arcuate zone in cerebral oedema. A much lesser difference in the water content of the corpus callosum $(73.3 \%)$ and the deep white matter $(71.2 \%)$ may be related to the less striking immunity to oedema of the former.

\section{REFERENCES}

Aleu, F. P., Katzman, R., and Terry, R. D. (1963). Fine structure and electrolyte analyses of cerebral edema induced by alkyl tin intoxication. J. Neuropath. exp. Neurol., 22, 403-413.

Bahr, G. F., Bloom, G., and Friberg, U. (1957). Volume changes of tissues in physiological fluids during fixation in osmium tetroxide or formaldehyde and during subsequent treatment. Exp. Cell Res., 12, 342-355.

Clasen, R. A., Cooke, P. M., Pandolfi, S., Boyd, D., and Raimondi, A. J. (1962). Experimental cerebral edema produced by focal freezing. I. An anatomic study utilizing vital dye techniques. J. Neuropath. exp. Neurol., 21, 579-596.

Feigin, I., (1965). The course and sequellae of brain edema. To be published as part of the reports of the Workshop on Brain Edema of the Problem Commission on Neuropathology of the World Federation of Neurology, September 11-13.

- and Popoff, N. (1962). Neuropathological observations on cerebral edema: The acute phase. Arch. Neurol. (Chic.), 6, 151-160.

- (1963). Neuropathological changes late in cerebral edema: The relationship to trauma, hypertensive disease and Binswanger's encephalopathy. J. Neuropath. exp. Neurol., 22, 500-511.

Flatau, E. (1897). Beitrag zur technischen Bearbeitung des Centralnervensystems. Anat. Anz., 13, 323-329.

Folch-Pi, J., and LeBaron, F. N. (1957). Chemical composition of the mammalian nervous system. In Metabolism of the Nervous System, pp. 67-71, edited by D. Richter. Pergamon Press, New York.

Gershenfeld, H. M., Wald, F., Zadunaisky, J. A., and de Robertis, E. P. D. (1959). Function of Astroglia in the Water-Ion Metabolism of the Central Nervous System. Neurology (Minneap.), 9, 412-425.

Gonatas, N. K., Zimmerman, H. M., and Levine, S. (1963). Ultrastructure of inflammation with edema in the rat brain. Amer. J. Path., 42, 455-469.

Greenfield, J. G. (1939). The histology of cerebral oedema associate with intracranial tumours (with special reference to changes is the nerve fibres of the centrum ovale). Brain, 62, 129-152.

Gross, W., and Lohaus, H. (1932). Untersuchungen über die Wirkur von Härtungsflüssigkeiten auf tierische Gewebe. $Z$. wis Mikroskop., 49, 168-190.

Hrdlicka, A. (1906). Brains and brain preservatives. Part I. Physicar changes in human and other brains collected under different conditions and preserved in various formalin preparationo Proc. U.S. nat. Mus., 30, 245-276.

Lagerlöf, H., and Torgersruud, T. (1934). Zur Kenntnis der Gewichts und Volumen-veränderungen bei Formalinfixation vo Gehirngewebe und der Einwirkung von $\mathrm{NaCl}-Z$ Zusatz darauf. J. Psychol. Neurol. (Lpz.), 46, 178-188.

Long, D. M., and Hartmann, J. F. (1965). The ulstrastructure of human cerebral edema. J. Neuropath. exp. Neurol., 24, 150-151.

Luse, S. A., and Harris, B. (1960). Electron microscopy of the brain in experimental edema. J. Neurosurg., 17, 439-446.

Mackay, R. P. (1962-63). Yearbook of Neurology, Psychiatry and Neurosurgery, p. 7, Year Book Medical Publishers, Chicago.

Perret, G. E., and Kernohan, J. W. (1943). Histopathologic changes of the brain caused by intracranial tumors (so-called edema or swelling of the brain). J. Neuropath. exp. Neurol., 2, 341-352.

Raimondi, A. J., Evans, J. P., and Mullan, S. (1962). Studies of cerebral edema. III. Alterations in the white matter: an electron microscopic study using Ferritin as a labelling compound. Acta neuropath. (Berl.), 2, 177-197.

Scheinker, I. M. (1947). Cerebral swelling: histopathology, classification and clinical significance of brain edema. J. Neurosurg. 4, 255-275.

Stewart-Wallace, A. M. (1939). A biochemical study of cerebral tissue, and of the changes in cerebral oedema. Brain, 62, 426438.

Torack, R. M., Terry, R. D., and Zimmerman, H. M. (1959). The fine structure of cerebral fluid accumulation. I. Swelling secondary to cold injury. Amer. J. Path., 35, 1135-1147.

,,$---(1960)$. The fine structure of cerebral fluid accumulation: II. Swelling produced by triethyl tin poisoning and it, comparison with that in the human brain. Amer. J. Path. 36, 273-287.

Zimmerman, H. M. (1964). Some contributions of electron microscopy to problems in pathology. The Twenty-Fourth Middleton Goldsmith Lecture. Bull. N.Y. Acad. Med., 40, 831-862.

Zülch, K. J. (1943). Hirnödem und Hirnschwellung. Virchows Arch. path. Anat., 310, 1-58.

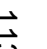

